NASA/CR-2005-214017

\title{
Mission Design for the Innovative Interstellar Explorer Vision Mission
}

Douglas I. Fiehler

QSS Group Inc., Cleveland, Ohio

Ralph L. McNutt, Jr.

Johns Hopkins University Applied Physics Laboratory, Laurel, Maryland 
Since its founding, NASA has been dedicated to the advancement of aeronautics and space science. The NASA Scientific and Technical Information (STI) Program Office plays a key part in helping NASA maintain this important role.

The NASA STI Program Office is operated by Langley Research Center, the Lead Center for NASA's scientific and technical information. The NASA STI Program Office provides access to the NASA STI Database, the largest collection of aeronautical and space science STI in the world. The Program Office is also NASA's institutional mechanism for disseminating the results of its research and development activities. These results are published by NASA in the NASA STI Report Series, which includes the following report types:

- $\quad$ TECHNICAL PUBLICATION. Reports of completed research or a major significant phase of research that present the results of NASA programs and include extensive data or theoretical analysis. Includes compilations of significant scientific and technical data and information deemed to be of continuing reference value. NASA's counterpart of peerreviewed formal professional papers but has less stringent limitations on manuscript length and extent of graphic presentations.

- TECHNICAL MEMORANDUM. Scientific and technical findings that are preliminary or of specialized interest, e.g., quick release reports, working papers, and bibliographies that contain minimal annotation. Does not contain extensive analysis.

- CONTRACTOR REPORT. Scientific and technical findings by NASA-sponsored contractors and grantees.
- CONFERENCE PUBLICATION. Collected papers from scientific and technical conferences, symposia, seminars, or other meetings sponsored or cosponsored by NASA.

- SPECIAL PUBLICATION. Scientific, technical, or historical information from NASA programs, projects, and missions, often concerned with subjects having substantial public interest.

- TECHNICAL TRANSLATION. Englishlanguage translations of foreign scientific and technical material pertinent to NASA's mission.

Specialized services that complement the STI Program Office's diverse offerings include creating custom thesauri, building customized databases, organizing and publishing research results ... even providing videos.

For more information about the NASA STI Program Office, see the following:

- Access the NASA STI Program Home Page at http://www.sti.nasa.gov

- E-mail your question via the Internet to help@sti.nasa.gov

- Fax your question to the NASA Access Help Desk at 301-621-0134

- Telephone the NASA Access Help Desk at 301-621-0390

- Write to:

NASA Access Help Desk

NASA Center for AeroSpace Information 7121 Standard Drive

Hanover, MD 21076 
NASA/CR-2005-214017

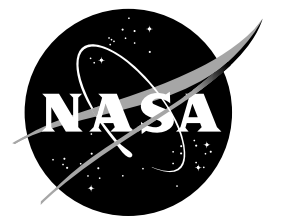

\section{Mission Design for the Innovative Interstellar Explorer Vision Mission}

Douglas I. Fiehler

QSS Group Inc., Cleveland, Ohio

Ralph L. McNutt, Jr.

Johns Hopkins University Applied Physics Laboratory, Laurel, Maryland

Prepared for the

29th International Electric Propulsion Conference

sponsored by ERPS, Princeton University, NASA Glenn, NASA Jet Propulsion

Laboratory, Aerojet, EPPDYL, IEPC, Busek, and Mitsubishi Electric

Princeton, New Jersey, October 31-November 4, 2005

Prepared under Contract NAS3-00145

National Aeronautics and

Space Administration

Glenn Research Center 


\section{Acknowledgments}

This work was supported by NASA “Vision Mission" grant NNG04GJ60G and NASA contract NAS3-00145. We acknowledge contributions of NASA Jet Propulsion Laboratory's Team-X.

Trade names or manufacturers' names are used in this report for identification only. This usage does not constitute an official endorsement, either expressed or implied, by the National Aeronautics and Space Administration.

Available from

NASA Center for Aerospace Information 7121 Standard Drive

Hanover, MD 21076
National Technical Information Service 5285 Port Royal Road Springfield, VA 22100 


\title{
Mission Design for the Innovative Interstellar Explorer Vision Mission
}

\author{
Douglas I. Fiehler \\ QSS Group, Inc. \\ Cleveland, Ohio 44135 \\ Ralph L. McNutt, Jr. \\ Johns Hopkins University \\ Applied Physics Laboratory \\ Laurel, Maryland 20723
}

\begin{abstract}
The Innovative Interstellar Explorer, studied under a NASA Vision Mission grant, examined sending a probe to a heliospheric distance of 200 Astronomical Units (AU) in a "reasonable" amount of time. Previous studies looked at the use of a near-Sun propulsive maneuver, solar sails, and fission reactor powered electric propulsion systems for propulsion. The Innovative Interstellar Explorer's mission design used a combination of a high-energy launch using current launch technology, a Jupiter gravity assist, and electric propulsion powered by advanced radioisotope power systems to reach $200 \mathrm{AU}$. Many direct and gravity assist trajectories at several power levels were considered in the development of the baseline trajectory, including single and double gravity assists utilizing the outer planets (Jupiter, Saturn, Uranus, and Neptune). A detailed spacecraft design study was completed followed by trajectory analyses to examine the performance of the spacecraft design options.
\end{abstract}

\section{Nomenclature}

Astronomical Unit, the mean distance between the Earth and Sun, $1.497959 \times 10^{8} \mathrm{~km}$ Electric Propulsion; use of a plasma or ion beam exhaust to propel a space vehicle Innovative Interstellar Explorer; an interstellar-precursor, robotic science mission using REP Specific impulse; ratio of thrust to the weight flow rate of propellant National Aeronautics and Space Administration Nuclear Electric Propulsion; the use of a nuclear fission reactor for energy to power an EP system Radioisotope Electric Propulsion; use of decay of radioisotopes for energy to power an EP system Radioisotope Power Source; a source of electricity that converts heat from radioisotope decay Radioisotope Thermoelectric Generator; an RPS using the Seebeck effect Stirling Radioisotope Generator; an RPS using a Stirling-cycle mechanical generator Technology Readiness Level; a measure of technology maturity

\section{Introduction}

A "interstellar precursor" mission has been under discussion in the science community for about 30 Ayears $1,2,3,4,5,6,7$. The mission concept is relatively simple, yet difficult to accomplish: leave the solar system as rapidly as possible to reach the interstellar medium as soon as possible, and provide in situ measurements of the outer planetary and near interstellar space along the way. Detailed science objectives have been discussed with appropriate instrumentation ${ }^{1,8}$. The scientific goals of such a mission have varied little over these decades. The most recent formulation includes ${ }^{1}$ : (1) explore the interstellar medium and determine directly the properties of the interstellar gas, the interstellar magnetic field, low-energy cosmic rays, and interstellar dust, (2) explore the influence of the interstellar medium on the solar system, its dynamics, and its evolution, (3) explore the impact of 
the solar system on the interstellar medium as an example of the interaction of a stellar system with its environment, and (4) explore the outer solar system in search of clues to its origin, and to the nature of other planetary systems. Given the desired distances involved for such a mission, here at least 200 Astronomical Units (AU), it is not surprising that the problem of implementing such a mission has always been one of propulsion, especially when one considers that a speed of $1 \mathrm{AU} / \mathrm{yr}$ is equivalent to $4.74 \mathrm{~km} / \mathrm{s}$.

Past concepts for such a mission have included the use of near-Sun powered gravity assists, with both chemical ${ }^{6}$ and advanced high-thrust systems $\mathrm{s}^{9,10,11,12,13,14,15}$, nuclear electric propulsion (NEP) $)^{2,3,4,16,17}$, and solar sails ${ }^{18,19}$. In this work, we detail the mission design studies for such a mission, dubbed the Innovative Interstellar Explorer (IIE) using radioisotope electric propulsion (REP) ${ }^{20}$. In an REP spacecraft, the power system mass is the major mass driver, and overall miniaturization, where possible, is paramount. The REP system can use any radioactive power supply (RPS) architecture. We assume that plutonium-238, the radioisotope used for the power supplies on Voyager, Galileo, Ulysses, and Cassini, will be used as the power source. A relatively high power output of at least $8 \mathrm{~W} / \mathrm{kg}$ (specific mass of $125 \mathrm{~kg} / \mathrm{kW}$ ) is required. This performance can, in principle, be obtained with either an advanced radioisotope thermoelectric generator (RTG) or a "next-generation" Stirling radioisotope generator (SRG) ${ }^{1}$.

To minimize the flight time to the interstellar medium, the outgoing asymptotic trajectory should be close to the direction of the incoming "interstellar wind" ${ }^{\prime 21,22,23,24,25}$. This direction, $252^{\circ}$ right ascension and $+7^{\circ}$ declination in Earth ecliptic coordinates defines the optimal aim point for the trajectory. Given the variability in the interaction region $^{26}$, however, a targeted trajectory within $\sim 20^{\circ}$ of this point will suffice. In particular, with this less stringent requirement, by remaining close to the plane of the ecliptic, the trajectory can be better optimized and also have a somewhat larger set of backup windows. The final requirement was thus to reach a point within $20^{\circ}$ of the incoming interstellar wind direction 200 AU from the Sun "as fast as possible."

\section{Mission Architecture}

Previous REP trajectory designs ${ }^{27,28,29,30,31,32}$ showed that because of the low-acceleration capability of REP a certain mission architecture is optimal for outer solar system missions. This approach, consisting of a high-excess escape energy $\left(\mathrm{C}_{3}\right)$ launch from Earth $\left(\mathrm{C}_{3} \geq 100 \mathrm{~km}^{2} / \mathrm{s}^{2}\right)$ followed by a long period of electric propulsion (EP) thrusting, has been shown to allow rendezvous of a small class spacecraft (dry mass less than $1000 \mathrm{~kg}$ ) with many bodies throughout the outer solar system ${ }^{32}$. Because of the similarities between the IIE mission and previously studied outer solar system missions, and because the IIE requires the minimum trip time to 200 A.U., a similar mission architecture was chosen.

The launch architecture chosen for the IIE provides more capability, but at a higher cost, than the previous studies $^{27,28,29,30,31,32}$. The outer solar system trajectories utilized an Atlas V 551 launch vehicle with a Star 48V upper stage to provide the required high $\mathrm{C}_{3}$. To minimize the IIE trip time, a Delta IV Heavy launch vehicle stacked with two solid propellant upper stages was used. The early studies that explored the mission trade space, utilized a Star 48/Star 37 stack, while the Advanced Project Design Team Studies upgraded to two Star 48A upper stages. Figure 1

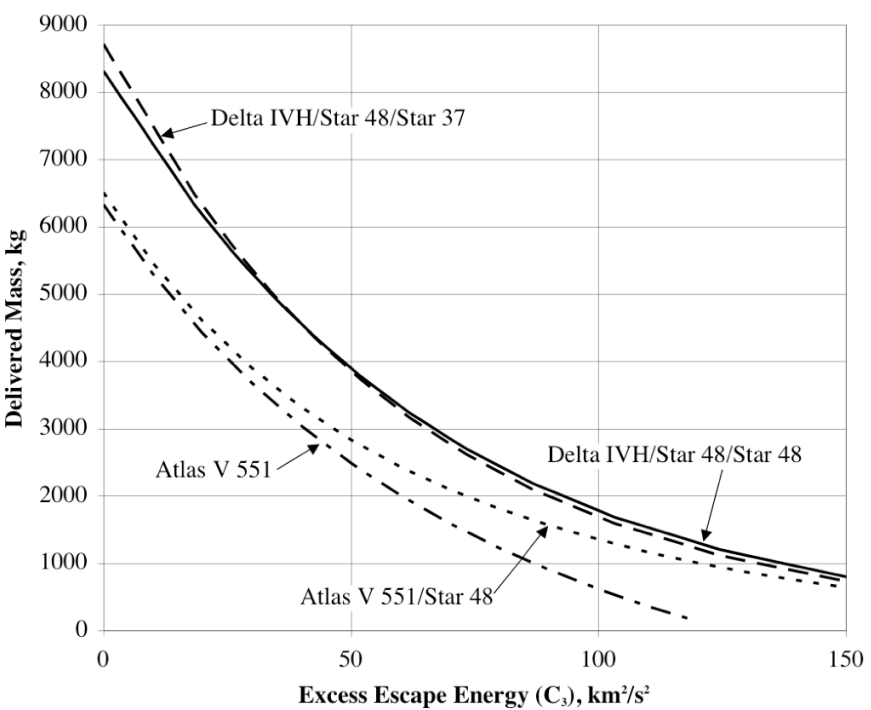

Figure 1. Comparison of Launch Architectures.

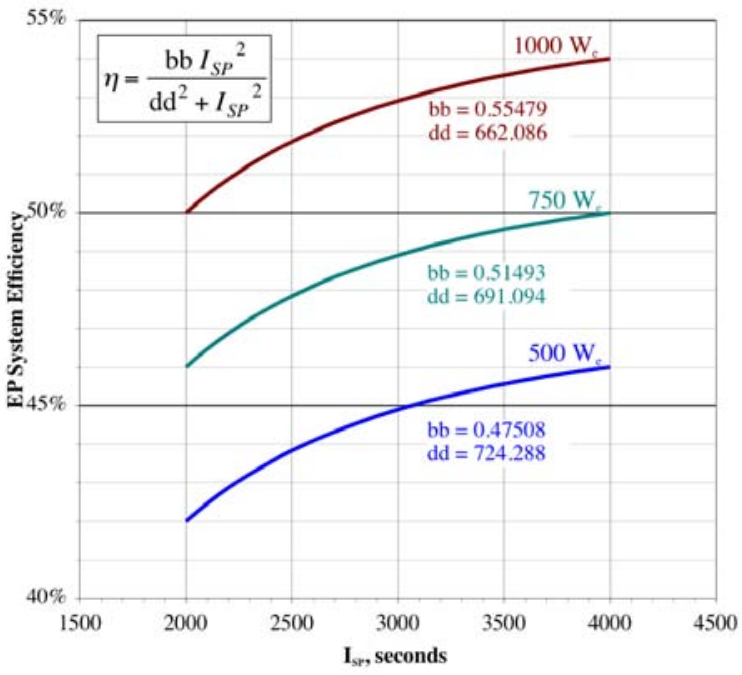

Figure 2. EP System Efficiency vs. ISP. 
displays the differences between the capabilities of these launch architectures $33,34,35,36$.

The EP system, which provides a significant proportion of the in-space $\Delta \mathrm{v}$, was included in the optimization by means of a simple EP model. This EP-system model used a theoretical performance model based on current best estimates of performance of low-power EP systems. The performance model, shown in Figure 2, relates efficiency to specific impulse $\left(I_{S P}\right)$ at power levels between $500 \mathrm{~W}_{\mathrm{e}}$ and $1000 \mathrm{~W}_{\mathrm{e}}$ into the EP system. These curves are representative of gridded-ion thrusters or Hall thrusters at these power levels. The specific thruster technology was chosen after an optimal $I_{S P}$ was determined for the mission. In all cases, the gridded-ion thruster was the technology of choice for the IIE mission because the $I_{S P}$ optimized too high for Hall thrusters to be considered feasible. The EP system mass model was based on mass estimates of a low-power gridded-ion propulsion system, with heritage from the NSTAR ${ }^{37}$ and $\mathrm{NEXT}^{38}$ programs, that is currently unfunded and, as a result, not developed. The power level chosen $\left(1000 \mathrm{~W}_{\mathrm{e}}\right.$ into the EP system) was chosen based on a trade of power level versus the number of RPS units that could reasonably be placed on a spacecraft. Early trajectory trades showed that power levels around $1000 \mathrm{~W}_{\mathrm{e}}$ seemed to be optimal based on mass estimates of the RPS units.

\section{Pathfinder Studies}

To begin the analysis on a purely trajectory-oriented basis, a study was conducted that analyzed many different trajectory options over many years of launch opportunities. A simple spacecraft model representing the IIE was generated with a dry mass of $519 \mathrm{~kg}$ and $1000 \mathrm{~W}_{\mathrm{e}}$ of power for propulsion. This dry mass was the final mass target for the trajectory analyses with the trip time minimized for each case. While only a simple mass model of the IIE spacecraft, it allowed analyses of a wide range of trajectories without the need to redesign the spacecraft for each case. This study of the trajectory design space enabled future analyses to be conducted more efficiently because the wide trajectory trade space was understood.

\section{A. Design Space}

The trajectory design space included a wide range of launch dates and trajectory types. Because various planetary flyby trajectories were planned for study and the final right ascension and declination were constrained, launch dates between 2010 and 2050 were considered. Minimum trip time trajectories that included single and double flybys of the outer planets (Jupiter, Saturn, Uranus, and Neptune) as well as direct trajectories were designed throughout the range of launch dates. No inner solar system gravity assists were considered to eliminate additional (and potentially massive) thermal requirements on the spacecraft design.

The sidereal period of the flyby planets and the constrained final right ascension and declination limit the launch opportunities for each trajectory type. Figure 3 shows the repetition patterns of each trajectory type studied. Note that the times and numbers of revolutions in Figure 3 are between timeoptimized launch opportunities. Non-timeoptimal trajectories can be found in the intervening years between time-optimal launch opportunities. Because of its mass, compared to the other outer planets, Jupiter provides the highest $\Delta \mathrm{v}$ to the spacecraft, followed by Saturn, Neptune, and Uranus. The gravity assist maneuvers also bend the spacecraft trajectory depending on the gravity assist altitude and incoming velocity, which adds some flexibility in trajectory design, allowing the gravity assist $\Delta \mathrm{v}$ to be traded for other parameters such as launch date, gravity

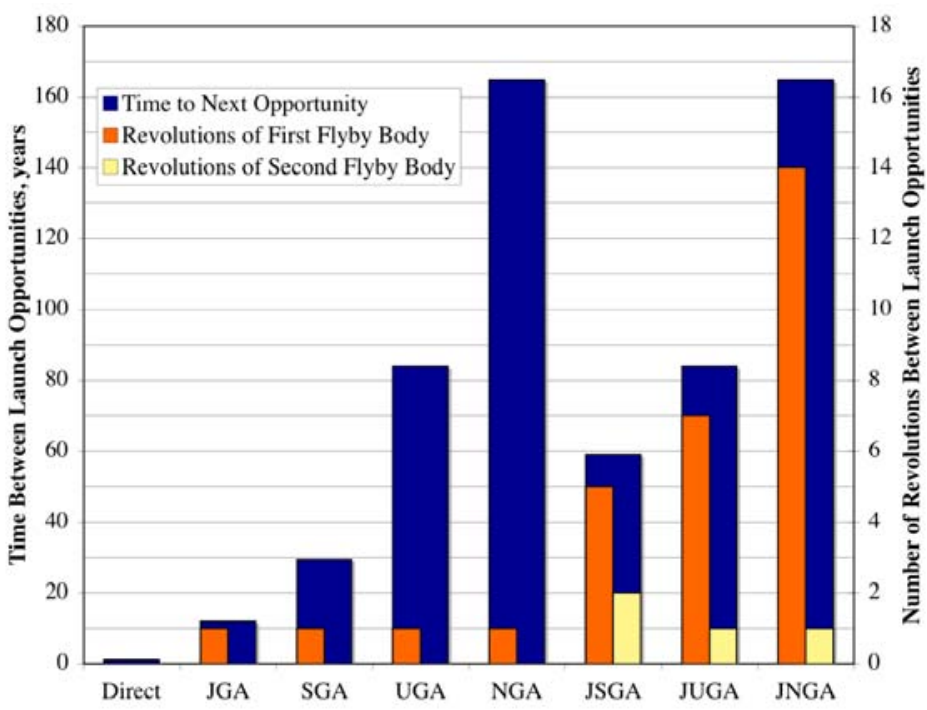

Figure 3. Trajectory Opportunity Repetition. assist date and total trip time.

\section{B. Trajectory Design Trades and Selection}

Three types of trajectories were studied; direct trajectories, single gravity assist trajectories, and double gravity assist trajectories. The direct trajectories were characterized by their high-energy launches followed by long 
thrusting periods that propelled the spacecraft to $200 \mathrm{AU}$. The single gravity assist trajectories utilized a high-energy launch followed by a gravity assist at Jupiter, Saturn, Uranus or Neptune. The double gravity assist trajectories also launched to a high energy Earth escape that was followed by a Jupiter gravity assist and a gravity assist at Saturn, Uranus, or Neptune. Figure 4 shows the trip times and launch years of the primary minimum-time trajectories. Other non-minimum time trajectories are available throughout the launch windows that extend from each of the launch dates in Figure 4. A summary of pertinent parameters for each of the trajectory types studied is presented in Table 1 and discussed throughout the remainder of this section.

The direct trajectory was the simplest and most flexible of the trajectories studied. It required a $\mathrm{C}_{3}$ of approximately $100 \mathrm{~km}^{2} / \mathrm{s}^{2}$, made one revolution around the Sun to achieve solar system escape velocity, and then proceeded to the heliospheric nose (see Figure 5). (Note that in all trajectory plots presented herein, a solid spacecraft trajectory line

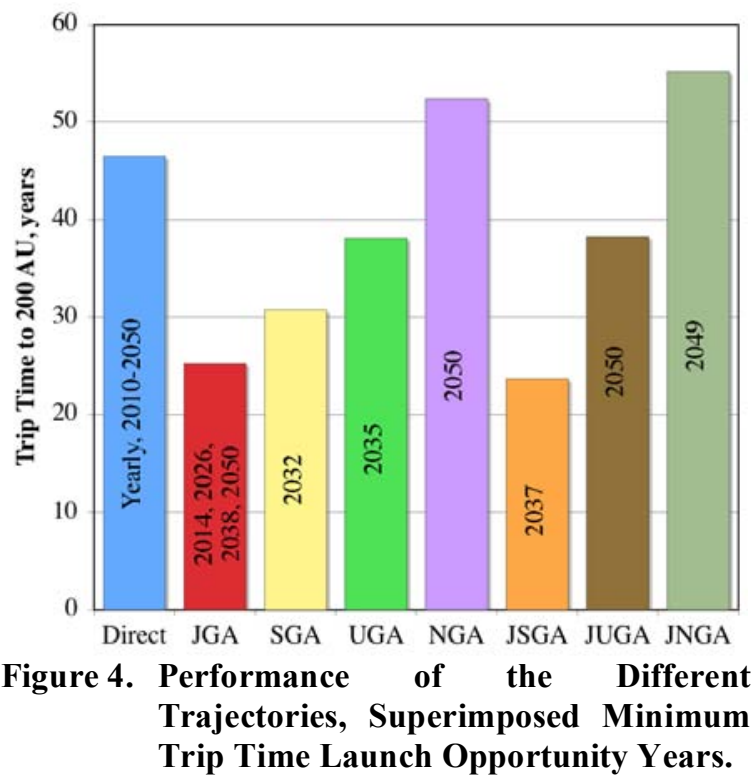

Table 1. Summary of Trajectories Parameters

\begin{tabular}{|c|c|c|c|c|c|c|c|c|}
\hline Trajectory Type & Direct & JGA & SGA & UGA & NGA & JSGA & JUGA & JNGA \\
\hline Launch Date & January 17,2010 & October 26, 2014 & August 26, 2032 & August 14,2035 & June 23,2050 & October 3, 2037 & January 23,2050 & December 18, 2049 \\
\hline First Gravity Assist Body & & Jupiter & Saturn & Uranus & Neptune & Jupiter & Jupiter & Jupiter \\
\hline Gravity Assist Date & & December 7, 2015 & April 11, 2035 & August 11, 2042 & May 2,2063 & November 7, 2038 & December 19, 2056 & June 6,2055 \\
\hline Gravity Assist Altitude & & $45388 \mathrm{~km}$ & $3027 \mathrm{~km}$ & $1286 \mathrm{~km}$ & $1261 \mathrm{~km}$ & $119726 \mathrm{~km}$ & $1059149 \mathrm{~km}$ & $965858 \mathrm{~km}$ \\
\hline Gravity Assist Radius & & $1.63 \mathrm{Rj}$ & $1.05 \mathrm{Rj}$ & $1.05 \mathrm{Rj}$ & $1.05 \mathrm{Rj}$ & $2.67 \mathrm{Rj}$ & $15.81 \mathrm{Rj}$ & $14.51 \mathrm{Rj}$ \\
\hline Gravity Assist $\Delta \mathrm{v}$ & & $28.0 \mathrm{~km} / \mathrm{s}$ & $19.9 \mathrm{~km} / \mathrm{s}$ & $13.8 \mathrm{~km} / \mathrm{s}$ & $13.3 \mathrm{~km} / \mathrm{s}$ & $24.3 \mathrm{~km} / \mathrm{s}$ & $9.6 \mathrm{~km} / \mathrm{s}$ & $10.2 \mathrm{~km} / \mathrm{s}$ \\
\hline First Gravity Assist Body & & & & & & \begin{tabular}{|c|} 
Saturn \\
\end{tabular} & Uranus & Neptune \\
\hline Gravity Assist Date & & & & & & December 20, 2039 & July 6,2062 & January 21,2071 \\
\hline Gravity Assist Altitude & & & & & & $8393 \mathrm{~km}$ & $1286 \mathrm{~km}$ & $1261 \mathrm{~km}$ \\
\hline Gravity Assist Radius & & & & & & $1.14 \mathrm{Rj}$ & $1.05 \mathrm{Rj}$ & $1.05 \mathrm{Rj}$ \\
\hline Gravity Assist $\Delta \mathrm{v}$ & & & & & & $23.5 \mathrm{~km} / \mathrm{s}$ & $14.2 \mathrm{~km} / \mathrm{s}$ & $14.5 \mathrm{~km} / \mathrm{s}$ \\
\hline Burnout Date & March 31, 2036 & November 2, 2029 & September 11, 2051 & June 22, 2060 & September 24,2085 & November 23, 2051 & December 3, 2069 & March 13, 2103 \\
\hline Burnout Distance & $66 \mathrm{AU}$ & $103 \mathrm{AU}$ & $99 \mathrm{AU}$ & $95 \mathrm{AU}$ & $82 \mathrm{AU}$ & $102 \mathrm{AU}$ & $61 \mathrm{AU}$ & $101 \mathrm{AU}$ \\
\hline Burnout Speed & $6.6 \mathrm{AU} /$ year & $9.5 \mathrm{AU} /$ year & $8.8 \mathrm{AU} /$ year & $8.1 \mathrm{AU} /$ year & $7.5 \mathrm{AU} /$ year & $10.3 \mathrm{AU} /$ year & $7.7 \mathrm{AU} / \mathrm{year}$ & 8.6 AU/year \\
\hline Date 200 AU Reached & July 8,2056 & January 12,2040 & May 23, 2063 & September 13,2073 & October 26,2102 & June 1,2061 & April 8, 2088 & February 20,2105 \\
\hline Trip Time to $200 \mathrm{AU}$ & 46.5 years & 25.2 years & 30.8 years & 38.1 years & 52.4 years & 23.7 years & 38.2 years & 55.2 years \\
\hline Speed at $200 \mathrm{AU}$ & 6.6 AU/year & $9.5 \mathrm{AU} /$ year & 8.7 AU/year & 8.1 AU/year & $7.5 \mathrm{AU} /$ year & 10.2 AU/year & 7.6 AU/year & 8.6 AU/year \\
\hline Azimuth at $200 \mathrm{AU}$ & $235.0^{\circ}$ & $254.8^{\circ}$ & $231.8^{\circ}$ & $231.8^{\circ}$ & $237.5^{\circ}$ & $263.5^{\circ}$ & $267.7^{\circ}$ & $232.2^{\circ}$ \\
\hline Elevation at $200 \mathrm{AU}$ & $0.0^{\circ}$ & $0.6^{\circ}$ & $7.4^{\circ}$ & $7.2^{\circ}$ & $21.3^{\circ}$ & $1.2^{\circ}$ & $3.3^{\circ}$ & $3.4^{\circ}$ \\
\hline Launch Mass & $1880 \mathrm{~kg}$ & $916 \mathrm{~kg}$ & $1387 \mathrm{~kg}$ & $1402 \mathrm{~kg}$ & $1307 \mathrm{~kg}$ & $900 \mathrm{~kg}$ & $1803 \mathrm{~kg}$ & $1541 \mathrm{~kg}$ \\
\hline Propellant Mass & $1361 \mathrm{~kg}$ & $397 \mathrm{~kg}$ & $868 \mathrm{~kg}$ & $883 \mathrm{~kg}$ & $788 \mathrm{~kg}$ & $381 \mathrm{~kg}$ & $1284 \mathrm{~kg}$ & $1022 \mathrm{~kg}$ \\
\hline Final Mass & $519 \mathrm{~kg}$ & $519 \mathrm{~kg}$ & $519 \mathrm{~kg}$ & $519 \mathrm{~kg}$ & $519 \mathrm{~kg}$ & $519 \mathrm{~kg}$ & $519 \mathrm{~kg}$ & $519 \mathrm{~kg}$ \\
\hline Power & $1.0 \mathrm{~kW}$ & $1.0 \mathrm{~kW}$ & $1.0 \mathrm{~kW}$ & $1.0 \mathrm{~kW}$ & $1.0 \mathrm{~kW}$ & $1.0 \mathrm{~kW}$ & $1.0 \mathrm{~kW}$ & $1.0 \mathrm{~kW}$ \\
\hline & $2563 \mathrm{~s}$ & $3654 \mathrm{~s}$ & $2748 s$ & $3133 \mathrm{~s}$ & $3981 \mathrm{~s}$ & $3616 \mathrm{~s}$ & $2279 \mathrm{~s}$ & $4304 \mathrm{~s}$ \\
\hline EP System Efficiency & $52.0 \%$ & $53.7 \%$ & $52.4 \%$ & $53.1 \%$ & $54.0 \%$ & $53.7 \%$ & $51.2 \%$ & $54.2 \%$ \\
\hline $\mathrm{C}_{3}$ & $103.9 \mathrm{~km}^{2} / \mathrm{s}^{2}$ & $152.4 \mathrm{~km}^{2} / \mathrm{s}^{2}$ & $124.4 \mathrm{~km}^{2} / \mathrm{s}^{2}$ & $123.7 \mathrm{~km}^{2} / \mathrm{s}^{2}$ & $128.4 \mathrm{~km}^{2} / \mathrm{s}^{2}$ & $153.6 \mathrm{~km}^{2} / \mathrm{s}^{2}$ & $106.7 \mathrm{~km}^{2} / \mathrm{s}^{2}$ & $117.3 \mathrm{~km}^{2} / \mathrm{s}^{2}$ \\
\hline $\mathrm{EP} \Delta \mathrm{v}$ & $32.4 \mathrm{~km} / \mathrm{s}$ & $20.3 \mathrm{~km} / \mathrm{s}$ & $26.5 \mathrm{~km} / \mathrm{s}$ & $30.5 \mathrm{~km} / \mathrm{s}$ & 36.1 km/s & $19.5 \mathrm{~km} / \mathrm{s}$ & $27.8 \mathrm{~km} / \mathrm{s}$ & $45.9 \mathrm{~km} / \mathrm{s}$ \\
\hline Thrust Time & 26.2 years & 15.0 years & 19.1 years & 24.9 years & 35.3 years & 14.1 years & 19.9 years & 53.3 years \\
\hline
\end{tabular}

indicates thrusting while a dashed line indicates a coast, and each plot contains tick marks spaced in time by oneyear intervals.) This trajectory was the most flexible because it did not require a planetary gravity assist, which allowed it to be launched in any year. However, this trajectory performed poorly with a trip time to $200 \mathrm{AU}$ of 46.5 years with a lightweight spacecraft model, but its velocity was twice that of the Voyager 2 spacecraft (see the column labeled "Direct" in Table 1).

Of the single gravity assist trajectories, the Jupiter Gravity Assist (JGA) trajectory had the shortest trip time, and second shortest trip time of all of the trajectories studied (see the columns labeled "JGA", "SGA", "UGA", and "NGA" in Table 1). For the Jupiter, Saturn, Uranus, and Neptune gravity assist trajectories, the trip times were 25.2, $30.8,38.1$ and 52.4 years, respectively. These trajectories all require a high- $\mathrm{C}_{3}$ launch (between 120 and $150 \mathrm{~km} / \mathrm{s}^{2}$ ), followed by a thrusting period to reach the gravity-assist body, followed first by the planetary gravity assist that provides a $\Delta \mathrm{v}$ of between 13.3 and $28.0 \mathrm{~km} / \mathrm{s}$, then by a long thrusting period until the propellant supply is depleted, and finally by a long coast to $200 \mathrm{AU}$ (see Figure 6). Only the JGA trajectory could accommodate more than one minimum-time launch opportunity during the 2010 - 2050 study window due to Jupiter's relatively short sidereal period of 11.9 years. The JGA trajectory can be launched in 2014, 2026, 2038, or 2050 and achieve performance 


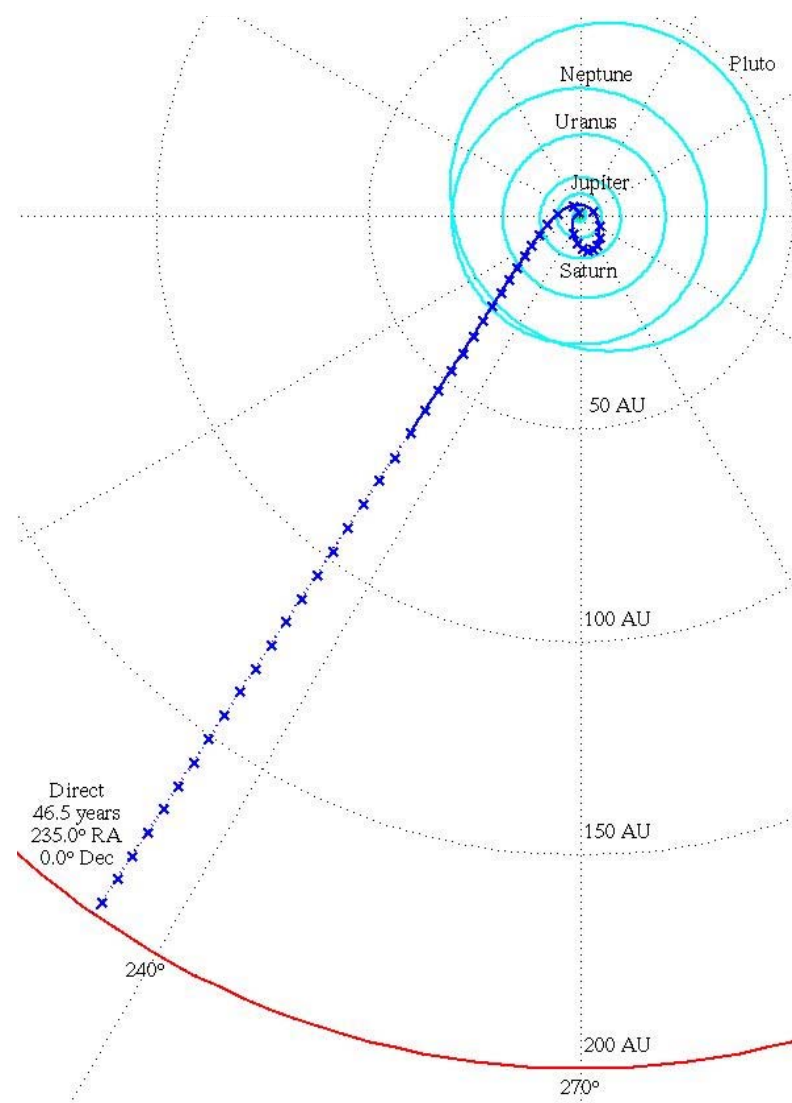

Figure 5. Direct Trajectory.

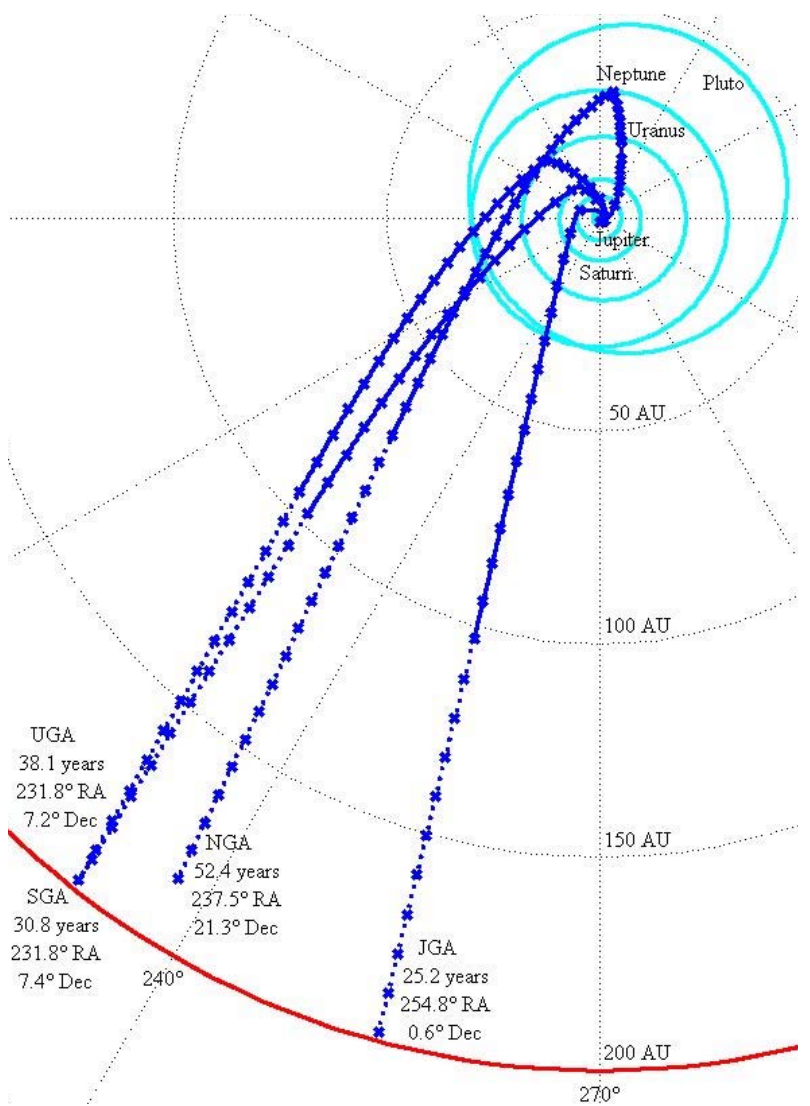

Figure 6. Single Gravity Assist Trajectories.

similar to that presented in Table 1. The other trajectories can accommodate launch opportunities in several years before and after the minimum-time launch year, due to the long periods of these outer planets, at the expense of longer trip time. Note that during the 2010-2050 time period, Neptune is in the wrong part of its orbit to provide any benefit. To affect a Neptune gravity assist, the spacecraft must travel approximately 30 AU away from the heliospheric nose, perform the Neptune gravity assist, and then traverse back through the solar system to reach 200 AU within the tolerance of the right ascension and declination targets.

The double gravity assist trajectories performed equivalently to the single gravity assist trajectories, except in the case of the Jupiter-Saturn Gravity Assist (JSGA) trajectory (see the columns labeled "JSGA", "JUGA", and "JNGA" in Table 1). Again, high energy launches were required for all trajectories $\left(106 \mathrm{~km}^{2} / \mathrm{s}^{2}<\mathrm{C}_{3}<154 \mathrm{~km} / \mathrm{s}^{2}\right)$, followed by thrusting periods to achieve each of the gravity assists, a long period of thrusting until all propellant is exhausted, and finally a long coast period to reach $200 \mathrm{AU}$ (see Figure 7). The trip times for the minimum-time double-gravity assist-trajectories are 23.7, 38.2, and 55.2 years for the Jupiter-Saturn, Jupiter-Uranus, and Jupiter-Neptune gravityassist trajectories, respectively. The JSGA trajectory has the shortest trip time of all trajectories studied, however only one opportunity exists to launch on this trajectory during the 40 -year window that was examined. The JupiterUranus and Jupiter-Neptune gravity assist trajectories' launch dates could be adjusted by Jupiter's sidereal period, because of the long sidereal periods of Uranus and Neptune, but penalties in trip time would be realized. Again, as with the single gravity assist trajectories, Neptune is in the wrong part of its orbit to provide any benefit in trip time during the 40-year study window.

The JGA trajectory was chosen for further study because of its near-minimum trip time, as compared to the other trajectories studied, and its minimum trip time launch window repetition every 11.9 years (Jupiter's sidereal period). Each minimum trip time launch window is approximately $20-25$ days long ( $\pm 10-12$ days) for a 6-month trip time penalty, and could be extended for additional trip time penalties. Around each minimum trip time launch opportunity are other launch opportunities with minimal trip time penalties each spaced by approximately 13 months (see Figure 9). These characteristics made the JGA trajectory the most feasible choice for further study.

Some room for improvement exists in the design of these trajectories without stretching the realm of technologies that could be available. One improvement would be a liquid upper stage to replace the two solid Star motors. This upper stage would have a higher $\mathrm{I}_{\mathrm{SP}}$ and thus provide more mass to the same required $\mathrm{C}_{3}$. $\mathrm{Spacecraft}$ 


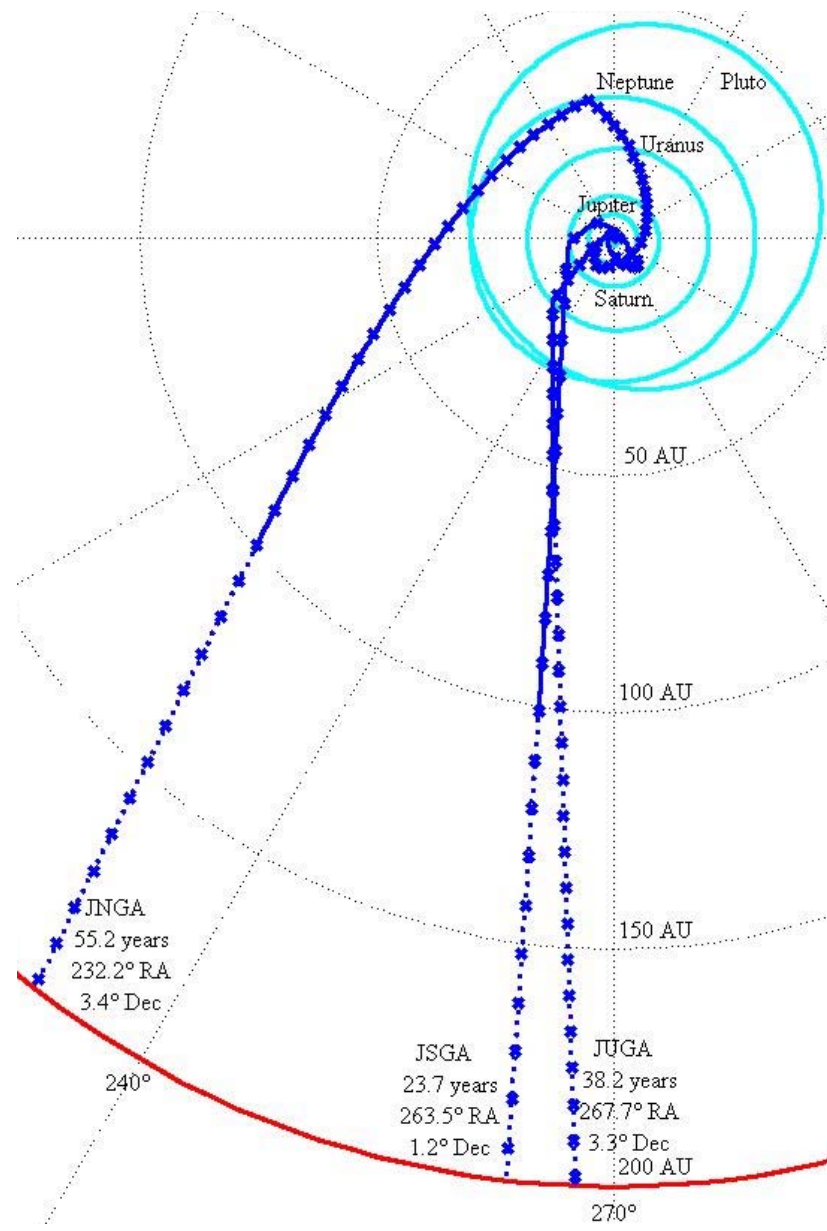

Figure 7. Double Gravity Assist Trajectories.

mass reductions would also improve the performance of these trajectories. Mass reductions could come in the form of technology improvements (higher RPS specific power) or design improvements (lighter structure, innovative spacecraft design).

\section{Jupiter Gravity Assist Design and Considerations}

The Jupiter gravity assist, used in many of these trajectories, adds complexity to the design. Not only does the JGA add constraints to the launch windows, but it also introduces a very inhospitable radiation environment to be traversed by the spacecraft ${ }^{39}$. To attain the maximum effect of the gravity assist, the minimum flyby radius was constrained at $1.05 \mathrm{R}_{\mathrm{J}}$, at the expense of time in the radiation belts. Figure 8 shows the JGA trajectory's Jupiter encounter within $10 R_{J}\left(0.5 R_{J}\right.$ outside of Europa) with tick-marks indicating time intervals of 15 minutes. In this case, the spacecraft reaches approximately $1.7 \mathrm{R}_{\mathrm{J}}$, receives a $\Delta \mathrm{v}$ of approximately $28 \mathrm{~km} / \mathrm{s}$, and has its trajectory turned by approximately $90^{\circ}$. For this Jupiter encounter, a total of approximately 13 hours are spent inside $10 \mathrm{R}_{\mathrm{J}}$, where most of the radiation exposure would occur. No analysis was performed to estimate the radiation dose or the amount of shielding needed on the spacecraft to protect sensitive components during the Jupiter encounter as part of this study. Note that this additional radiation shielding design consideration is not pertinent to the other outer planets due to their lack of significant radiation environments.

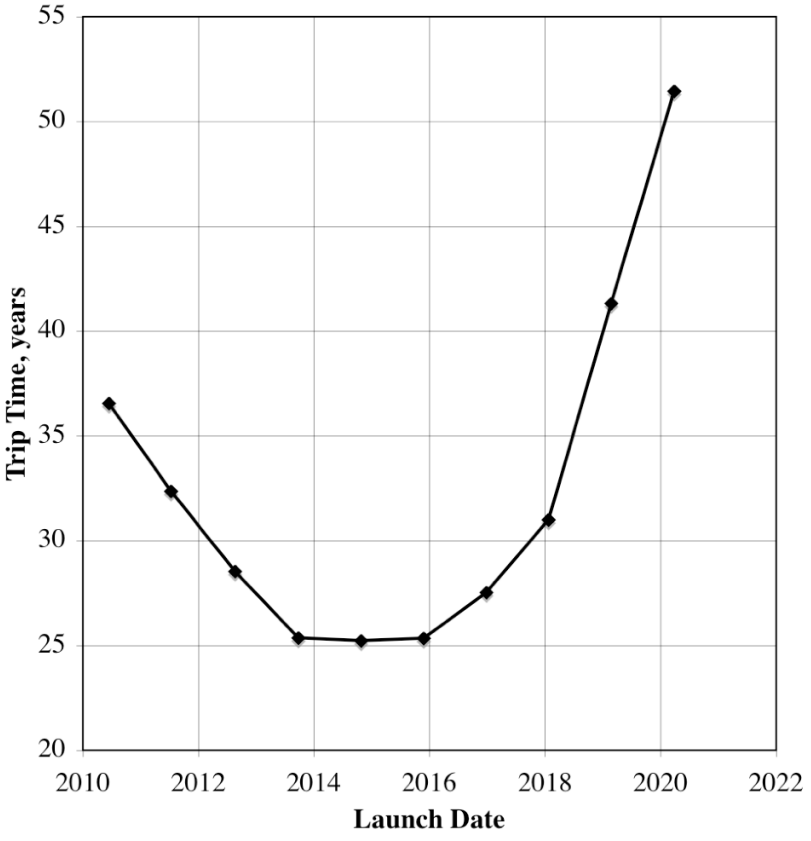

Figure 9. Jupiter Gravity Assist Trajectory Trip Time vs. Launch Date

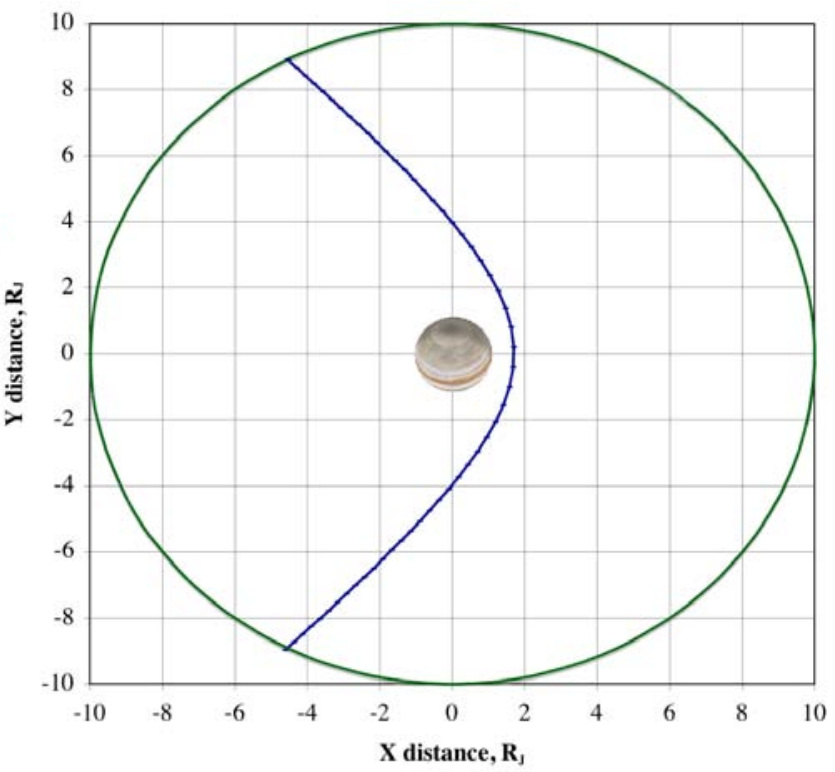

Figure 8. Jupiter Flyby Trajectory Inside $10 R_{J}$ with 15-minute Interval Tick-Marks 


\section{Advanced Project Design Team Studies}

To add more detail to the spacecraft design used in these pathfinder studies, a study was conducted with the Jet Propulsion Laboratory's (JPL's) Advanced Project Design Team (Team-X). The goal of this study was to create detailed spacecraft designs using existing and in-development technologies while adding sufficient margins/reserves according to JPL's Design Principles. The technology cut-off date for these studies is 2010 (technology must be at a technology readiness level (TRL) of 6), sufficient to provide the necessary technology for a 2014 launch date.

\section{A. Spacecraft Design Options}

Four options were investigated during the study. All options used the same architecture configuration, subsystem design, and baseline (JGA) mission design. Different technology and data rate assumptions drove the design of the 4 options. The baseline design (Option 1) relies on current state-of-the-art technology and does not make any aggressive technology assumptions, except for the power system - an advanced, high-temperature RTG. A downlink data rate of $5.8 \mathrm{kbps}$ from $200 \mathrm{AU}$ is assumed. This rate is sufficient to downlink data collected continuously at a rate of 500 bps with two downlinks of $\sim 7$ hours per week to 180 phased $12-\mathrm{m}$ antennas operating at Ka-band. The spacecraft has a $2.1-\mathrm{m}$ diameter high gain antenna and carries three $1-\mathrm{kW}$ ion thrusters, one being a spare. Four, fully redundant command and data subsystems (CDS) are used to deal with reliability questions for a $\sim 30$-year flight time.

The second study option is a delta from the baseline that investigates more aggressive technology and redundancy assumptions. Only two CDS strings and two thrusters are included. The high-gain antenna is increased to a $3-\mathrm{m}$ diameter to compensate for other (mass and power reducing) system changes. The option 2 spacecraft is presented in Figure $10^{1}$. The spacecraft design of the other options is based on this spacecraft with modifications based on the technology and redundancy choices made for each option.

Option 3 studies whether reducing the return data rate to $500 \mathrm{bps}$ (from $5.8 \mathrm{kbps}$ in Options 1 and 2) saves significant mass and power and, hence, reduces trip time. The decreased data rate only saves around $20 \mathrm{~kg}$ of dry mass on the spacecraft from the baseline design.

Option 4 combines the aggressive technology in Option 2, the reduced data rate of Option 3 , and a reduced ion thruster power that ultimately results in a dry mass $170 \mathrm{~kg}$ less than that of the baseline design.

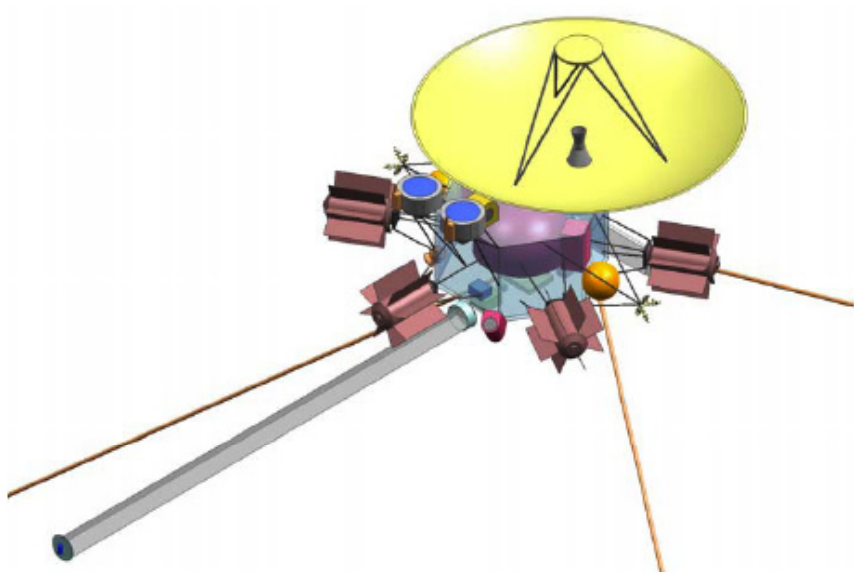

Figure 10. Option 2 Spacecraft Design ${ }^{1}$.

Table 2. Option Trades for Spacecraft System Design.

\begin{tabular}{|c|c|c|c|c|c|c|c|c|c|c|c|c|}
\hline & \begin{tabular}{|c|}
$\begin{array}{c}\text { Option } 1 \\
\text { Mass }\end{array}$ \\
\end{tabular} & $\begin{array}{c}\text { Option } 2 \\
\text { Mass } \\
\end{array}$ & $\begin{array}{c}\text { Option } 3 \\
\text { Mass } \\
\end{array}$ & $\begin{array}{c}\text { Option } 4 \\
\text { Mass } \\
\end{array}$ & \begin{tabular}{|c|} 
Subsystem \\
Contingency \\
\end{tabular} & \begin{tabular}{|c|} 
CBE+ \\
Contingency \\
\end{tabular} & $\begin{array}{c}\text { Mode 1 } \\
\text { Power }\end{array}$ & $\begin{array}{c}\text { Mode 2 } \\
\text { Power }\end{array}$ & $\begin{array}{c}\text { Mode 3 } \\
\text { Power }\end{array}$ & $\begin{array}{c}\begin{array}{c}\text { Mode 4 } \\
\text { Power }\end{array} \\
\end{array}$ & $\begin{array}{c}\text { Mode 5 } \\
\text { Power } \\
\end{array}$ & $\begin{array}{c}\text { Mode 6 } \\
\text { Power }\end{array}$ \\
\hline Description & Baseline & $\begin{array}{c}\text { Aggressive } \\
\text { Technology } \\
\text { Assumptions }\end{array}$ & $\begin{array}{c}\text { Reduced } \\
\text { Downlink } \\
\text { Rate }\end{array}$ & $\begin{array}{c}\text { Combination } \\
\text { of Options } 2 \\
\text { and } 3\end{array}$ & & & Safing & $\begin{array}{l}\text { Telecom } \\
\text { after EP } \\
\text { Burnout }\end{array}$ & $\begin{array}{c}\begin{array}{c}\text { Engine-off } \\
\text { Cruise }\end{array} \\
\end{array}$ & \begin{tabular}{|c|} 
Engine-on \\
Cruise 10 AU \\
to EP \\
Burnout \\
\end{tabular} & Launch & \begin{tabular}{|r|} 
Telecom \\
before EP \\
Burnout
\end{tabular} \\
\hline \begin{tabular}{|l|} 
Payload \\
Instruments \\
Payload Total \\
\end{tabular} & $\begin{array}{l}35 \mathrm{~kg} \\
35 \mathrm{~kg} \\
\end{array}$ & $\begin{array}{l}35 \mathrm{~kg} \\
35 \mathbf{~ k g} \\
\end{array}$ & $\begin{array}{l}35 \mathrm{~kg} \\
35 \mathrm{~kg}\end{array}$ & $\begin{array}{l}35 \mathrm{~kg} \\
\mathbf{3 5} \mathbf{~ k g} \\
\end{array}$ & $\begin{array}{l}30 \% \\
\mathbf{3 0 \%} \\
\end{array}$ & $\begin{array}{l}46 \mathrm{~kg} \\
46 \mathrm{~kg}\end{array}$ & $\begin{array}{l}9.1 \mathrm{~W} \\
\mathbf{9 . 1} \mathrm{W} \\
\end{array}$ & $\begin{array}{l}29.4 \mathrm{~W} \\
29.4 \mathrm{~W} \\
\end{array}$ & $\begin{array}{l}29.4 \mathrm{~W} \\
29.4 \mathrm{~W} \\
\end{array}$ & $\begin{array}{l}29.4 \mathrm{~W} \\
29.4 \mathrm{~W}\end{array}$ & $\begin{array}{l}0.0 \mathrm{~W} \\
\mathbf{0 . 0} \mathrm{W}\end{array}$ & $\begin{array}{l}29.4 \mathrm{~W} \\
29.4 \mathrm{~W} \\
\end{array}$ \\
\hline Bus & & & & & & & & & & & & \\
\hline $\begin{array}{l}\text { Attitude Control } \\
\text { Command \& Data } \\
\text { Power } \\
\text { Propulsion1 } \\
\text { Propulsion2 } \\
\text { Structures \& Mechanisms } \\
\text { Cabling } \\
\text { Telecomm } \\
\text { Thermal } \\
\text { Bus Total }\end{array}$ & $\begin{array}{l}15 \mathrm{~kg} \\
26 \mathrm{~kg} \\
182 \mathrm{~kg} \\
81 \mathrm{~kg} \\
10 \mathrm{~kg} \\
126 \mathrm{~kg} \\
38 \mathrm{~kg} \\
23 \mathrm{~kg} \\
48 \mathrm{~kg} \\
\mathbf{5 4 9} \mathbf{~ k g} \\
\end{array}$ & $\begin{array}{c}7 \mathrm{~kg} \\
14 \mathrm{~kg} \\
182 \mathrm{~kg} \\
62 \mathrm{~kg} \\
10 \mathrm{~kg} \\
110 \mathrm{~kg} \\
30 \mathrm{~kg} \\
24 \mathrm{~kg} \\
42 \mathrm{~kg} \\
\mathbf{4 8 1} \mathrm{kg} \\
\end{array}$ & $\begin{array}{c}15 \mathrm{~kg} \\
26 \mathrm{~kg} \\
182 \mathrm{~kg} \\
81 \mathrm{~kg} \\
10 \mathrm{~kg} \\
124 \mathrm{~kg} \\
37 \mathrm{~kg} \\
21 \mathrm{~kg} \\
38 \mathrm{~kg} \\
\mathbf{5 3 5} \mathbf{~ k g} \\
\end{array}$ & $\begin{array}{l}7 \mathrm{~kg} \\
14 \mathrm{~kg} \\
155 \mathrm{~kg} \\
59 \mathrm{~kg} \\
10 \mathrm{~kg} \\
99 \mathrm{~kg} \\
28 \mathrm{~kg} \\
21 \mathrm{~kg} \\
35 \mathrm{~kg} \\
\mathbf{4 2 8} \mathrm{kg} \\
\end{array}$ & $\begin{array}{l}21 \% \\
30 \% \\
30 \% \\
20 \% \\
18 \% \\
30 \% \\
30 \% \\
20 \% \\
30 \% \\
28 \% \\
\end{array}$ & $\begin{array}{c}18 \mathrm{~kg} \\
34 \mathrm{~kg} \\
237 \mathrm{~kg} \\
97 \mathrm{~kg} \\
12 \mathrm{~kg} \\
164 \mathrm{~kg} \\
49 \mathrm{~kg} \\
28 \mathrm{~kg} \\
62 \mathrm{~kg} \\
701 \mathrm{~kg} \\
\end{array}$ & $\begin{array}{c}9.0 \mathrm{~W} \\
43.0 \mathrm{~W} \\
10.1 \mathrm{~W} \\
0.7 \mathrm{~W} \\
41.0 \mathrm{~W} \\
0.0 \mathrm{~W} \\
\\
17.0 \mathrm{~W} \\
34.5 \mathrm{~W} \\
\mathbf{1 5 5 . 2} \mathrm{W} \\
\end{array}$ & $\begin{array}{c}36.0 \mathrm{~W} \\
43.0 \mathrm{~W} \\
46.0 \mathrm{~W} \\
0.7 \mathrm{~W} \\
41.0 \mathrm{~W} \\
0.0 \mathrm{~W} \\
\\
522.6 \mathrm{~W} \\
34.5 \mathrm{~W} \\
\mathbf{7 2 3 . 8 ~ W} \\
\end{array}$ & $\begin{array}{c}36.0 \mathrm{~W} \\
43.0 \mathrm{~W} \\
10.4 \mathrm{~W} \\
0.7 \mathrm{~W} \\
1.0 \mathrm{~W} \\
0.0 \mathrm{~W} \\
\\
17.0 \mathrm{~W} \\
32.0 \mathrm{~W} \\
\mathbf{1 4 0 . 0 ~ W}\end{array}$ & $\begin{array}{c}36.0 \mathrm{~W} \\
43.0 \mathrm{~W} \\
11.4 \mathrm{~W} \\
0.7 \mathrm{~W} \\
1.0 \mathrm{~W} \\
0.0 \mathrm{~W} \\
\\
17.0 \mathrm{~W} \\
47.5 \mathrm{~W} \\
\mathbf{1 5 6 . 5 ~ W} \\
\end{array}$ & \begin{tabular}{|c|}
$40.0 \mathrm{~W}$ \\
$43.0 \mathrm{~W}$ \\
$8.2 \mathrm{~W}$ \\
$0.7 \mathrm{~W}$ \\
$1.0 \mathrm{~W}$ \\
$0.0 \mathrm{~W}$ \\
\\
$17.0 \mathrm{~W}$ \\
$23.8 \mathrm{~W}$ \\
$\mathbf{1 3 3 . 6 \mathrm { W }}$ \\
\end{tabular} & $\begin{array}{c}36.0 \mathrm{~W} \\
43.0 \mathrm{~W} \\
46.5 \mathrm{~W} \\
0.7 \mathrm{~W} \\
41.0 \mathrm{~W} \\
0.0 \mathrm{~W} \\
\\
517.0 \mathrm{~W} \\
47.5 \mathrm{~W} \\
731.6 \mathrm{~W}\end{array}$ \\
\hline & & & & & & & & & & & & \\
\hline $\begin{array}{l}\text { Spacecraft Total (Dry) } \\
\text { Subsystem Heritage Contingency } \\
\text { System Contingency } \\
\text { Spacecraft with Contingency } \\
\text { Xenon Propellant } \\
\text { Hydrazine Propellant } \\
\text { Spacecraft Total (Wet) } \\
\end{array}$ & \begin{tabular}{|c|}
$\mathbf{5 8 5} \mathbf{~ k g}$ \\
$162 \mathrm{~kg}$ \\
$13 \mathrm{~kg}$ \\
$\mathbf{7 6 0} \mathbf{~ k g}$ \\
$459 \mathrm{~kg}$ \\
$31 \mathrm{~kg}$ \\
$\mathbf{1 2 5 0} \mathbf{~ k g}$ \\
\end{tabular} & $\begin{array}{c}516 \mathrm{~kg} \\
145 \mathrm{~kg} \\
10 \mathrm{~kg} \\
\mathbf{6 7 1} \mathrm{kg} \\
450 \mathrm{~kg} \\
31 \mathrm{~kg} \\
1151 \mathrm{~kg}\end{array}$ & \begin{tabular}{|l}
$\mathbf{5 7 0} \mathbf{~ k g}$ \\
$158 \mathrm{~kg}$ \\
$13 \mathrm{~kg}$ \\
$\mathbf{7 4 1} \mathbf{~ k g}$ \\
$461 \mathrm{~kg}$ \\
$31 \mathrm{~kg}$ \\
$\mathbf{1 2 3 2} \mathbf{~ k g}$
\end{tabular} & $\begin{array}{c}\mathbf{4 6 3} \mathbf{~ k g} \\
129 \mathrm{~kg} \\
10 \mathrm{~kg} \\
\mathbf{6 0 2} \mathbf{~ k g} \\
394 \mathrm{~kg} \\
31 \mathrm{~kg} \\
\mathbf{1 0 2 6} \mathbf{~ k g} \\
\end{array}$ & $28 \%$ & $747 \mathrm{~kg}$ & \begin{tabular}{|c|}
$164.3 \mathrm{~W}$ \\
$49.3 \mathrm{~W}$ \\
$213.6 \mathrm{~W}$
\end{tabular} & $\begin{array}{l}753.2 \mathrm{~W} \\
\\
225.9 \mathrm{~W} \\
\mathbf{9 7 9 . 1} \mathrm{W}\end{array}$ & $\begin{array}{c}169.4 \mathrm{~W} \\
\\
50.8 \mathrm{~W} \\
220.3 \mathrm{~W}\end{array}$ & $\begin{array}{c}185.9 \mathrm{~W} \\
\\
55.8 \mathrm{~W} \\
241.7 \mathrm{~W}\end{array}$ & \begin{tabular}{|l}
$133.6 \mathrm{~W}$ \\
\\
$40.1 \mathrm{~W}$ \\
$173.6 \mathrm{~W}$
\end{tabular} & $\begin{array}{l}\text { 761.0 W } \\
\\
228.3 \mathrm{~W} \\
\mathbf{9 8 9 . 4} \mathrm{W}\end{array}$ \\
\hline
\end{tabular}


The high gain antenna is $2.1-\mathrm{m}$ in diameter, $2 \mathrm{CDS}$ strings are used, and two $750 \mathrm{~W}$ ion thrusters are used for propulsion.

In each case, power requirements for six operational power modes were evaluated and design reserves/margins were applied in accord with the technology readiness levels and design rules used by JPL's Team-X. Also, the overall mission design was re-optimized in each case assuming a "best launch date" in 2014 and a Jupiter gravity assist. Details for each option at the system level are given in Table 2.

\section{B. Trajectory Performance Using Advanced Project Design Team Spacecraft Design}

Because more mass is required to be delivered to $200 \mathrm{AU}$ than in the pathfinder studies, the trip times for the design options in Table 2 are longer. Using the spacecraft designs and technology assumptions in Options 1, 2, 3, and 4, the respective trip times are 31.1 years, 29.7 years, 30.7 years and 29.9 years (see Table 3). Optimization of each system-design option yields trajectories with a launch date in October of 2014 and that arrive at 200 AU between June 2044 and November of 2045 with Jupiter gravity assists in either January or February of 2016. The parameters that affect the trajectory were all held constant for options 1 through 3, except for the final mass (dry mass) delivered to $200 \mathrm{AU}$, explaining the trip time differences between these options. Option 4 also decreased the power available to the EP system. This change decreased the level of acceleration the EP system could provide and also decreased the dry mass of the spacecraft, which resulted in a similar trip time to option 2. Each of these options result in a final velocity relative to the Sun of 7.6 to 8.0 AU/year (nearly 2.5 times the speed of Voyager 2, now 3.3 AU/yr and more than twice that of Voyager 1, now about $3.6 \mathrm{AU} / \mathrm{yr}$ ) and all within $15^{\circ}$ of the target right ascension and declination.

\begin{tabular}{|c|c|c|c|c|}
\hline & Option 1 & Option 2 & Option 3 & Option 4 \\
\hline Launch Date & October 22, 2014 & October 22,2014 & October 22,2014 & October 23,2014 \\
\hline Gravity Assist Body & Jupiter & Jupiter & Jupiter & Jupiter \\
\hline Gravity Assist Date & February 13, 2016 & January 29, 2016 & February 10, 2016 & January 16, 2016 \\
\hline Gravity Assist Altitude & $79131 \mathrm{~km}$ & $71970 \mathrm{~km}$ & $77736 \mathrm{~km}$ & $65629 \mathrm{~km}$ \\
\hline Gravity Assist Radius & $2.11 \mathrm{R}_{\mathrm{J}}$ & $2.01 \mathrm{R}_{\mathrm{J}}$ & $2.09 \mathrm{R}_{\mathrm{J}}$ & $1.92 \mathrm{R}_{\mathrm{J}}$ \\
\hline Gravity Assist $\Delta v$ & $23.3 \mathrm{~km} / \mathrm{s}$ & $24.2 \mathrm{~km} / \mathrm{s}$ & $23.5 \mathrm{~km} / \mathrm{s}$ & $25.0 \mathrm{~km} / \mathrm{s}$ \\
\hline Burnout Date & April 15, 2033 & June 19,2032 & February 4, 2033 & October 16,2032 \\
\hline Burnout Distance & $105 \mathrm{AU}$ & $104 \mathrm{AU}$ & $104 \mathrm{AU}$ & $107 \mathrm{AU}$ \\
\hline Burnout Speed & $7.6 \mathrm{AU} /$ year & 8.0 AU/year & 7.7 AU/year & $7.9 \mathrm{AU} /$ year \\
\hline Date 200 AU Reached & November 4, 2045 & June 11, 2044 & July 11,2045 & September 10, 2044 \\
\hline Trip Time to $200 \mathrm{AU}$ & 31.1 years & 29.7 years & 30.7 years & 29.9 years \\
\hline Speed at $200 \mathrm{AU}$ & 7.6 AU/year & 8.0 AU/year & $7.7 \mathrm{AU} /$ year & $7.8 \mathrm{AU} /$ year \\
\hline Azimuth at $200 \mathrm{AU}$ & $265.1^{\circ}$ & $262.8^{\circ}$ & $264.7^{\circ}$ & $261.2^{\circ}$ \\
\hline Elevation at $200 \mathrm{AU}$ & $0.0^{\circ}$ & $0.0^{\circ}$ & $0.0^{\circ}$ & $0.0^{\circ}$ \\
\hline Launch Mass & $1281 \mathrm{~kg}$ & $1193 \mathrm{~kg}$ & $1265 \mathrm{~kg}$ & $1068 \mathrm{~kg}$ \\
\hline Xenon Propellant Mass & $459 \mathrm{~kg}$ & $450 \mathrm{~kg}$ & $461 \mathrm{~kg}$ & $394 \mathrm{~kg}$ \\
\hline Final Mass & $843 \mathrm{~kg}$ & $758 \mathrm{~kg}$ & $824 \mathrm{~kg}$ & $686 \mathrm{~kg}$ \\
\hline Power & $1.0 \mathrm{~kW}$ & $1.0 \mathrm{~kW}$ & $1.0 \mathrm{~kW}$ & $0.75 \mathrm{~kW}$ \\
\hline & $3862 \mathrm{~s}$ & $3789 \mathrm{~s}$ & $3830 \mathrm{~s}$ & $3524 \mathrm{~s}$ \\
\hline EP System Efficiency & $53.9 \%$ & $53.8 \%$ & $53.9 \%$ & $49.6 \%$ \\
\hline Total Stack $\mathrm{C}_{3}$ & $120.6 \mathrm{~km}^{2} / \mathrm{s}^{2}$ & $125.8 \mathrm{~km}^{2} / \mathrm{s}^{2}$ & $121.5 \mathrm{~km}^{2} / \mathrm{s}^{2}$ & $132.7 \mathrm{~km}^{2} / \mathrm{s}^{2}$ \\
\hline Delta IV $\mathrm{H} \mathrm{C}_{3}$ & $16.3 \mathrm{~km}^{2} / \mathrm{s}^{2}$ & $17.1 \mathrm{~km}^{2} / \mathrm{s}^{2}$ & $16.5 \mathrm{~km}^{2} / \mathrm{s}^{2}$ & $18.1 \mathrm{~km}^{2} / \mathrm{s}^{2}$ \\
\hline Delta IV H Launch Mass & $6906 \mathrm{~kg}$ & $6803 \mathrm{~kg}$ & $6887 \mathrm{~kg}$ & $6678 \mathrm{~kg}$ \\
\hline $\mathrm{EP} \Delta \mathrm{v}$ & $15.9 \mathrm{~km} / \mathrm{s}$ & $16.8 \mathrm{~km} / \mathrm{s}$ & $16.1 \mathrm{~km} / \mathrm{s}$ & $15.3 \mathrm{~km} / \mathrm{s}$ \\
\hline Thrust Time & 18.5 years & 17.7 years & 18.3 years & 18.0 years \\
\hline
\end{tabular}

\section{Conclusion}

A mission beyond the edge of the solar system to interstellar space has been a desire of the science community for decades, and achieving the science goals in a "reasonable" amount of time has been a challenge as shown in previous studies. This study explores the trajectory trade space through analysis of direct, single-gravity-assist, and double-gravity-assist trajectories to $200 \mathrm{AU}$. The trajectory chosen as the baseline for this study, the Jupiter gravityassist trajectory, has one of the shortest trip times of those trajectories studied and the most flexible launch opportunities. This baseline trajectory, flown with a light small spacecraft ( $\sim 520 \mathrm{~kg}$ dry mass), could reach $200 \mathrm{AU}$ within the right ascension and declination constraints in approximately 25 years. A spacecraft design study was conducted to add considerations of technology readiness, margins, and physical layout of the spacecraft systems with a technology cut-off date of 2010 (TRL 6). This design study resulted in spacecraft dry masses approximately 140-320 kg higher than used in the initial trajectory trade study. This mass increase results in trip times approximately 5 years longer for a total of approximately 30 years to reach 200 AU. Whether this trip time is "reasonable" will have to be determined by the science community and programmatic considerations. The twin Voyager spacecraft have been flying for over 25 years and have a potential lifetime of 15 years more until their decaying RTG power output can no longer run them. Following their "Grand Tour" of the outer planets, the spacecraft have remained at the scientific cutting edge while continuing to excite the public imagination. The Innovative Interstellar Explorer would be a worthy successor to the Voyagers, and their predecessors Pioneers 10 and 11, in taking the first scientific step to the stars. The required technology to reach $200 \mathrm{AU}$ and the interstellar medium either exists or can be developed in time for a 2014 launch with the proper interest, funding, and commitment to scientific discovery and the next generation of space explorers. 


\section{References}

${ }^{1}$ McNutt, R. L., Leary, J. C., Gold, R. E., Krimigis, S. M., Roelof, E. C., Gruntman, M., Gloeckler, G., Koehn, P. L., Kurth, W. S., Oleson, S. R., Fiehler, D. I., "Innovative Interstellar Explorer: Radioisotope Propulsion to the Interstellar Medium," AIAA-2005-4272, 41 $1^{\text {st }}$ AIAA/ASME/SAE/ASEE Joint Propulsion Conference and Exhibit, Tucson, AZ, July 2005.

2 Jaffe, L. D., and Ivie, C. V., "Science aspects of a mission beyond the planets," Icarus, Vol. 39, 1979, pp.486-494.

${ }^{3}$ Jaffe, L. D. and Norton, H. N., “A prelude to interstellar flight,” Astro. Aero., Vol. 18, 1980, pp.38-44.

${ }^{4}$ Jaffe, L. D., Ivie, C., Lewis, J. C., Lipes, R., Norton, H. N., Stearns, J. W., Stimpson, L. D., and Weissman, P., “An interstellar precursor mission," J. Brit. Int.. Soc., Vol. 33, 1980, pp.3-26.

${ }^{5}$ T.E. Holzer, et al. The Interstellar Probe: Scientific objectives for a Frontier mission to the heliospheric boundary and interstellar space, NASA Publication, 1990.

${ }^{6}$ R.A. Mewaldt, J. Kangas, S.J. Kerridge, and M. Neugebauer, A small interstellar probe to the heliospheric boundary and interstellar space, Acta Astron., 35, Suppl., 267-276, 1995.

${ }^{7}$ McNutt, R. L., Jr., Gold, R. E., Roelof, E. C., Zanetti, L. J., Reynolds, E. L., Farquhar, R. W., Gurnett, D. A., and Kurth, W. S., "A sole/ad astra: From the Sun to the stars," J. Brit. Inter. Soc., Vol. 50, 1997, pp. 463-474.

${ }^{8}$ Mewaldt, R.A., and Liewer, P.A., "Scientific payload for an Interstellar probe mission," The Outer Heliosphere: The Next Frontier, Pergamon, 2001, pp.451-464.

${ }^{9}$ R.L. McNutt, Jr., G. B. Andrews, J. McAdams, R. E. Gold, A. Santo, D. Oursler, K. Heeres, M. Fraeman, and B. Williams, A realistic interstellar explorer, Proceedings of the Space Technology and Applications International Forum 2000, edited by M. S. El-Genk, American Institute of Physics, New York, 2000.

${ }^{10}$ McNutt, R. L., Jr., Andrews, G. B. McAdams, J., Gold, R. E., Santo, A., Oursler, D., Heeres, K., Fraeman, M., and Williams, B., "A realistic interstellar probe," COSPAR Colloquium on The Outer Heliosphere: The Next Frontiers, COSPAR Colloquia Series, Vol. 11, K. Scherer, H. Fichtner, H.-J. Fahr, and E. Marsch, eds., Pergamon Press, New York, 2002, Vol. 11, pp. 431-434.

${ }^{11}$ Lyman, R. W., Ewing, M. E. Krishnan, R. S. Lester, D. M. and McNutt, R. L., Jr., "Solar thermal propulsion for an interstellar probe," AIAA 2001-3377, 37 $7^{\text {th }}$ AIAA/ASME/SAE/ASE Joint propulsion Conference, Salt Lake City, Utah, July 8-11, 2001.

${ }^{12}$ McNutt, R. L., Jr., Andrews, G. B., McAdams, J. V., Gold, R. E., Santo, A. G., Ousler, D. A., Heeres, K. J., Fraeman, M. E., and Williams, B. D., "Low-cost interstellar probe," Acta Astron., Vol. 52, 2003, pp. 267-279.

${ }^{13}$ McNutt, R. L., Jr., Andrews, G. B., Gold, R.E., Santo, A. G., Bokulic, R. S., Boone, B. G., Haley, D. R., McAdams, J. V., Fraeman, M. E., Williams, B. D., Boyle, M. P., Lester, D., Lyman, R., Ewing, M., Krishnan, R., Read, D., Naes, L., McPherson, M., and Deters, R., "A realistic interstellar explorer," in AIP Conference Proceedings (Solar Wind 10), edited by M. Velli et al., Vol. 679, New York: American Institute of Physics, 2003, pp. 830-833.

${ }^{14}$ McAdams, J. V., and McNutt, R. L. Jr., "Ballistic Jupiter gravity-assist, perihelion- $\Delta \mathrm{V}$ trajectories for an interstellar explorer,” J. Astron. Sci., Vol. 51, 2003, pp.179-193.

${ }^{15}$ McNutt, R. L., Jr., G. B., Andrews, G. B., Gold, R.E., Bokulic, R. S., Boone, B. G., Haley, D. R., McAdams, J. V., Williams, B. D., Boyle, M. P., Starstrom, G., Riggin, J, Lester, D., Lyman, R., Ewing, M., Krishnan, R., Read, D., Naes, L., McPherson, M., and Deters, R., “A realistic interstellar explorer,” Adv. Space Res., Vol. 34, 2004, pp.192-197.

${ }^{16}$ Pawlik, E. V., and Phillips, W. M., "A nuclear electric propulsion vehicle for planetary exploration," J. Spacecraft Rockets, Vol., 14, 1977, pp.518-525.

17 Nock, K. T., "TAU - A mission to a thousand astronomical units," $19^{\text {th }}$ AIAA/DGLR/JSASS International Electric Propulsion Conference, Colorado Springs, CO, AIAA-87-1049, May 11-13, 1987.

${ }_{18}$ Mewaldt, R. A., and Liewer, P. C., "An interstellar probe mission to the boundaries of the heliosphere and nearby interstellar space," AIAA-2000-5173, AIAA Space 2000, 19-21 September 2000, Long Beach, California.

${ }^{19}$ Liewer, P. C., Mewaldt, R. A., Ayon, J. A., Garner, C., Gavit, S., and Wallace, R. A., "Interstellar probe using a solar sail: Conceptual design and technological challenges," COSPAR Colloquium on The Outer Heliosphere: The Next Frontiers, COSPAR Colloquia Series, Vol. 11, K. Scherer, H. Fichtner, H.-J. Fahr, and E. Marsch, eds., Pergamon, New York, 2001, pp.411-420.

${ }^{20}$ Noble, R. J., "Radioisotope electric propulsion of sciencecraft to the outer solar system and near-interstellar space," Acta Astron., Vol. 44, 1999, pp.193-199.

${ }^{21}$ P.C. Frisch, Characteristics of nearby interstellar medium, Space Sci. Rev., 72, 499-592, 1995.

${ }^{22}$ D. Breitschwerdt, The local bubble, Space Sci. Rev., 78, 173-182, 1996.

${ }^{23}$ G.P. Zank, Interaction of the solar wind with the local interstellar medium: A theoretical perspective, Space Sci. Rev., 89, $1-275,1999$.

${ }^{24}$ McNutt, Jr., R. L., Lyon, J. , and Goodrich, C. C., "3D MHD Simulations of the Heliosphere-VLISM Interaction," AIP Conf. Proc. (Solar Wind 9), Vol. CP471, 1999, pp. 823-826.

${ }^{25}$ McNutt, R. L., Jr., "Modeling charge exchange in the solar wind/VLISM interaction," Physics of the Outer Heliosphere, Third International IGPP Conf., Florinski, V., Pogorelov, N. V., and G. P. Zank, eds., Vol. CP719, 2004, pp. 111-116.

${ }^{26}$ Krimigis, S. M., Decker, R. B., Hill, M. E., Armstrong, T. P., Gloeckler, G., Hamilton, D. C., Lanzerotti, L. J., and Roelof, E. C., "Voyager 1 exited the solar wind at a distance $\sim 85$ AU from the Sun," Nature, Vol., 426, 2003, pp. 45-48.

${ }^{27}$ Oleson, S.R., Gefert, L., Schreiber, J., McAdams, J., "Sub-Kilowatt Radioisotope Electric Propulsion for Outer Solar System Exploration", Forum on Innovative Approaches to Outer Planetary Exploration 2001-2020, Lunar and Planetary Institute, Houston, Texas, Feb, 2001. 
${ }^{28}$ Oleson, S.R., Gefert, L., Patterson, M., Schreiber, J., Benson, S., McAdams, J., Ostdiek, P., “Outer Planet Exploration with Advanced Radioisotope Electric Propulsion", IEPC-2001-0179, 27 ${ }^{\text {th }}$ International Electric Propulsion Conference, Pasadena, CA, October 2001.

${ }^{29}$ Oleson, S.R., Benson, S., Gefert, L., Patterson, M., Schreiber, J., "Radioisotope Electric Propulsion for Fast Outer Planetary Orbiters", AIAA-2002-3967, 38 ${ }^{\text {th }}$ AIAA/ASME/SAE/ASEE Joint Propulsion Conference, Indianapolis, IN, July 2002.

${ }^{30}$ Fiehler, D. I., Oleson, S. R., "Mission Steering Profiles of Outer Planetary Orbiters Using Radioisotope Electric Propulsion," Proceedings of the Space Technology and Applications International Forum 2004, edited by M. S. El-Genk, American Institute of Physics, New York, 2004, also NASA TM-2004-212877, January 2004.

${ }^{31}$ Fiehler, D. I., Oleson, S. R., "Neptune Orbiters Utilizing Solar and Radioisotope Electric Propulsion," AIAA-2004-3978, $40^{\text {th }}$ AIAA/ASME/SAE/ASEE Joint Propulsion Conference and Exhibit, Fort Lauderdale, FL, July 2004.

${ }^{32}$ Fiehler, D. I., Oleson, S. R., "Radioisotope Electric Propulsion Missions Utilizing A Common Spacecraft Design," Acta Astron., Vol. 57, No. 2-8, 2005, pp.444-454.

${ }^{33}$ International Launch Systems (ILS), “Atlas Launch System Planner’s Guide,” Rev. 9, September 2001.

${ }^{34}$ Morton Thiokol, Inc., "Space Rocket Motors," June 1987.

${ }^{35}$ The Boeing Company, "Delta IV Payload Planner's Guide," MDC 00H0043, October 2000.

${ }^{36}$ The Boeing Company, "Delta IV Payload Planner's Guide Update - April 2002,” MDC 00H0043, April 2002.

${ }^{37}$ Polk, J. E., Kakuda, R. Y., Anderson, J. R., Brophy, J. R., Rawlin, V. K., Patterson, M. J., Sovey, J., Hamley, J., "Performance of the NSTAR Ion Propulsion System on the Deep Space One Mission," AIAA-2001-965, 39 $9^{\text {th }}$ Aerospace Sciences Meeting and Exhibit, Reno, NV, January 2001.

${ }^{38}$ Benson, S., Patterson, M., Vaughan, D., Wilson, A., Wong, B., "NASA's Evolutionary Xenon Thruster (NEXT) Phase 2 Development Status," AIAA-2005-4070, 41 ${ }^{\text {st }}$ AIAA/ASME/SAE/ASEE Joint Propulsion Conference and Exhibit, Tucson, AZ, July 2005.

${ }^{39}$ De Angelis, G., Clowdsley, M. S., Nealy, J. E., Tripathi, R. K., Wilson, J. W., "Radiation Analysis for Manned Missions to the Jupiter System," Advances in Space Research, Vol. 34, No. 6, 2004, pp. 1395-1403. 


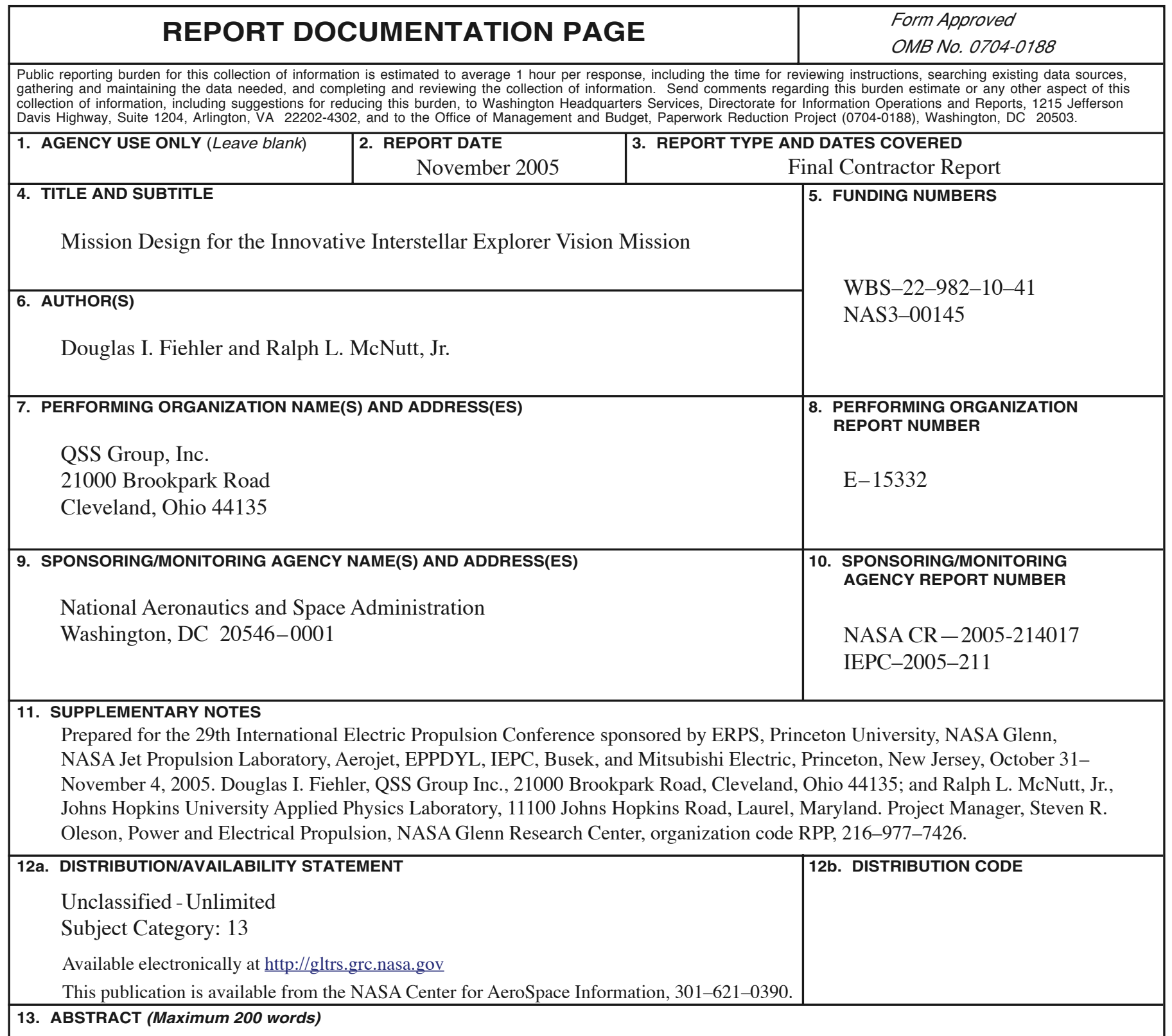

The Innovative Interstellar Explorer, studied under a NASA Vision Mission grant, examined sending a probe to a heliospheric distance of 200 Astronomical Units (AU) in a "reasonable" amount of time. Previous studies looked at the use of a near-Sun propulsive maneuver, solar sails, and fission reactor powered electric propulsion systems for propulsion. The Innovative Interstellar Explorer's mission design used a combination of a high-energy launch using current launch technology, a Jupiter gravity assist, and electric propulsion powered by advanced radioisotope power systems to reach 200 AU. Many direct and gravity assist trajectories at several power levels were considered in the development of the baseline trajectory, including single and double gravity assists utilizing the outer planets (Jupiter, Saturn, Uranus, and Neptune). A detailed spacecraft design study was completed followed by trajectory analyses to examine the performance of the spacecraft design options.

\section{SUBJECT TERMS}

Trajectories; Electric propulsion; Interstellar precursor mission

\begin{tabular}{|c|c|c|c|}
\hline $\begin{array}{c}\text { 17. SECURITY CLASSIFICATION } \\
\text { OF REPORT } \\
\text { Unclassified }\end{array}$ & $\begin{array}{c}\text { 18. SECURITY CLASSIFICATION } \\
\text { OF THIS PAGE } \\
\text { Unclassified }\end{array}$ & $\begin{array}{c}\text { 19. SECURITY CLASSIFICATION } \\
\text { OF ABSTRACT } \\
\text { Unclassified }\end{array}$ \\
\hline
\end{tabular}



